\title{
The Cost of Bearing Witness to the Environmental Crisis : \\ Vicarious Traumatization and Dealing with Secondary \\ Traumatic Stress among Environmental Researchers
}

\author{
Pihkala, Panu
}

2020

Pinkala , P 2020 , ' The Cost of Bearing Witness to the Environmental Crisis : Vicarious

Traumatization and Dealing with Secondary Traumatic Stress among Environmental

Researchers ' , Social Epistemology : a journal of knowledge, culture and policy , vol. 34 , no. 1 , pp. 86-100 . https://doi.org/10.1080/02691728.2019.1681560

http://hdl.handle.net/10138/329686

https://doi.org/10.1080/02691728.2019.1681560

unspecified

acceptedVersion

Downloaded from Helda, University of Helsinki institutional repository.

This is an electronic reprint of the original article.

This reprint may differ from the original in pagination and typographic detail.

Please cite the original version. 


\section{The Cost of Bearing Witness to the Environmental Crisis: \\ Vicarious Traumatization and Dealing with Secondary Traumatic Stress among Environmental Researchers}

Panu Pihkala ${ }^{\mathrm{a} *}$

Final draft, published in Social Epistemology 34:1, 86-100.

https://doi.org/10.1080/02691728.2019.1681560

${ }^{a}$ Faculty of Theology, University of Helsinki, Finland

*Faculty of Theology, P.O. Box 4, 00014 University of Helsinki; panu.pihkala@ helsinki.fi

Dr. Panu Pihkala is a postdoctoral researcher who has specialized in the psychosocial and spiritual dimensions of environmental problems. Pihkala has written extensively on 'eco-anxiety', environmental education, and spirituality. He is a leading Finnish expert in the psychosocial dimensions of climate change and serves as an expert in many projects. He was awarded the national prize for adult education (Sivistyspalkinto) in 2018 for his work on eco-anxiety and hope.

ORCID: 0000-0002-6876-8011 


\begin{abstract}
Researchers working on environmental issues are often unprepared to deal with the traumatic potential of their studies. They often face traumatic encounters in their first-hand experiences in fieldwork, for example, by finding animals killed by poachers or seeing the disastrous effects of climate change. However, environmental researchers also suffer from forms of secondary trauma or vicarious trauma related to environmental problems when they become affected by hearing or reading about the suffering of others. Unfortunately, however, very little support structures exist for students and researchers who experience secondary trauma. This article discusses the phenomenon of secondary trauma among researchers and students of environmental science. Through an analysis of existing empirical studies, the article highlights that there are clear signs of traumatic symptoms among environmental researchers. The most common reactions include psychic numbing, compassion fatigue, and burnouts. The article also makes suggestions for recognizing vulnerabilities, and for enhancing resilience through self-care. Since traumatic exposure by environmental researchers has not been systematically studied or discussed in detail in the existing literature, this article makes a significant contribution to the field showcasing ideas for further research, including possible empirical studies on the ways in which trauma and secondary trauma feature among environmental researchers.
\end{abstract}

Keywords: ecological trauma; researcher; emotion; climate change

\title{
1. Introduction
}

The whole idea that environmental issues ${ }^{1}$ can be traumatizing may appear as a remote possibility to many. While research on this topic is still sporadic, there is a growing international interest in the study of 'ecological trauma' since 2010s (Woodbury 2019; Wright 2017; White 2015). In this research, several factors have been identified that may cause trauma for environmental researchers, including changes in the environment, but also an awareness of related social and ecological dynamics. 
The stress and trauma related impacts of environmental change have been studied from multiple standpoints. First, because the number and intensity of global environmental problems is growing constantly, there is also a growing number of health impacts on people. For a long time, research remained concentrated on impacts on physical health, but during the last ten years the subject of mental health impacts of environmental problems has received growing attention. A special focus has rested on the discussion of climate change because its impacts are vast and multiple, and because it is connected to numerous other environmental problems (for overviews of climate change and mental health, see Clayton, Manning, Krygsman and Speiser [2017]; Berry, Waite, Capon and Murray [2018]). However, the focus of this article is on the impacts of secondary trauma on environmental researchers, including the traumatic effects of extreme weather events and more general 'climate trauma'.

Second, traditional ways of conceptualizing trauma have been shaped by a strong anthropocentrism (Brennan 2015). The result of this mindset has been a tendency to think that only inter-human experiences can cause traumas. The only exception to this kind of anthropocentric bias are so-called natural disasters, and their traumatic effects have been well studied (see, e.g., Parkes [2015]). But the idea that environmental problems themselves might cause traumas has not been discussed even by most researchers of natural disasters.

Regarding trauma theory, it is significant that the term 'ecological' has been used, but the theory does not refer to environmental problems; instead it refers to an approach which tries to understand the complexity and existence of multiple interconnected factors in phenomena related to trauma (Collins and Collins 2005; Harvey and Tummala-Narra 2007). ${ }^{2}$ It is only in the 2010s that we see some scholars start to develop theories of ecological trauma as related to environmental problems (Wright 2017).

Strong anthropocentrism has been challenged in many fields (Brennan 2015). Various proposals and movements champion less anthropocentric approaches. These include the influential 
posthumanism movement (for an introduction, see Mahon 2017). Posthumanism argues that humans are deeply interconnected with other forms of life and other parts of the ecosystem. Thus, it studies or discusses the kind of matters that traditional humanism or humanistic studies (humanities) did, but it distances itself from any anthropocentric humanism. In various posthumanistic literature, there is much discussion about emotional connections between humans and the non-human world or the more-than-human world.

These views encourage discussion on new forms of ecological trauma: traumas that are generated by the experience of damage inflicted upon non-human creatures and places. For example, multidisciplinary environmental humanities scholar Kate Wright defines ecological trauma in this manner as: 'Understanding ecological trauma as a breakdown of connectivities makes sense of the personal anguish that often accompanies environmental devastation and redefines ecological damage as a multispecies experience that is psychological as well as biological.' (Wright 2017, 74; cf. Woodbury 2011)

Another recent discourse is the study of 'climate trauma', that is, the ways in which climate change in general is related to trauma. In the recent past, interesting discussions of climate trauma have featured in studies within the environmental humanities (Richardson 2018; Kaplan 2016; Morton 2013) and in psychology. Ecopsychologists Benjamin White (2015) and Chiva Woodbury (2019, 2018, 2016), as well as psychoanalyst and philosopher Donna Orange (2017) have made pioneering contributions to this discourse.

The discussions about ecological trauma are deeply connected with definitions of trauma. While there is a general understanding that trauma is related to any event exceeding the individual's ability to meet its demands (Herman 1992), scholars such as Ellis and Knight $(2018,3)$ point out that 'despite the term's popularity, there is little consensus as to its precise meaning'. Traumas are often separated into primary and secondary trauma (Ellis and Knight 2018), and primary trauma can 
be further separated into type 1 trauma (resulting from a sudden event) and type 2 trauma (chronic exposure to potentially traumatizing events) (Terr 1991).

The variety of ways in which trauma can be defined is a very important point with regards to ecological trauma. Many kinds of events and consequences may be approached by using trauma theories. What emerges as crucial is: a) an effort to practice clarity and rigor in arguments; and b) a sincere effort to better understand trauma-like phenomena by applying various theories to empirical evidence. In this article, I use the term ecological trauma widely, referring to any events and consequences related to environmental problems which may cause trauma symptoms. By using this term broadly, I mean to include potentially traumatic events that are discussed by various scholars using various terms, such as climate trauma. There is clearly a need to develop a more precise terminology and a more encompassing theoretical framework regarding the varieties of ecological trauma, but this task is beyond the scope of this article.

The concept of secondary trauma is even more difficult to define in a clear manner. Several researchers have helpfully discussed alternative terminology, related phenomena, and various scholarly proposals (Branson 2018; Ellis and Knight 2018, 3; Salston and Figley 2003). Several related terms have also been used, most importantly vicarious traumatization (VT), compassion fatigue, and secondary traumatic stress (STS). I here follow Branson's view which draws an analytic distinction between between VT and STS. All of these phenomena happen vicariously, that is, by witnessing traumatic suffering by someone else. While many symptoms are similar, an important difference is that VT requires long-term exposure, while STS and compassion fatigue can develop afterwards without an ongoing emphatic relationship with a source of trauma such as a suffering other. While burnout is another condition which requires long-term exposure, its symptoms are different, and it is considered easier to alleviate (Branson 2018, 2, 4).

Trauma scholar Figley (1999, 10, quoted in Whitt-Woosley and Sprang 2018, 477) provides a useful definition which applies to both vicarious traumatization and secondary traumatic stress: 
"the natural, consequent behaviors and emotions resulting from knowledge about a traumatizing event experienced by a significant other," which includes symptoms similar to those found in people directly exposed to trauma, such as intrusive imagery, hyperarousal, and avoidance'. Thus, trauma is not simply an illness or something abnormal, but a rather normal reaction to events with a high enough shock value.

With regard to ecological trauma, the phrasing 'a significant other' is crucial. As discussed above, most research on trauma focuses on human others - often called 'victims' in theories of STS - but it is possible to extend the discussion to different kinds of others as well. In addition, some theories, like Posthumanism, challenge the strong presupposed distinctions between self and other. In these theories, trauma can be seen as something which happens to both others and to self at the same time; perhaps in various measures, but nonetheless in a shared way. This could be analyzed by applying the literature on 'shared trauma', 'shared traumatic reality' and 'double exposure' (for these framings, see Branson 2018, 3). However, I mostly leave this theme for further research because adequately dealing with it would require more space than I have here.

STS has mostly been researched with regard to helping professionals, such as 'counselors, social workers, healthcare professionals, first responders, and humanitarian workers' (WhittWoosley and Sprang 2018, 476-477). There is very little explicit discussion of secondary traumatic stress and vicarious traumatization related to environmental themes. Psychologist have briefly noted that the indirect impacts of climate change can include 'vicarious psychological trauma' (Doherty and Clayton 2011, 266). In her recent book about the challenges of emotional resilience and climate change, written especially for clinicians, Leslie Davenport includes a short subchapter (of the length of one page) on 'Vicarious traumatization' and discusses compassion fatigue. Davenport (2017, 4344) points out that therapists are in danger of VT and STS in relation to climate change: 'Not only will we be experiencing our own emotional reactions to climate issues, we also run the risk of secondary or vicarious trauma as we witness additional suffering and trauma in others.' 
There is even less discussion about STS and VT among environmental researchers, which is explained partly by the relatively new character of the entire field of studies on ecological trauma. Database searches such as 'environmental researcher / environmentalist / conservationist / climate scientist' and 'trauma' do not yield much results. Thus, the present article can be seen as a first attempt of spearheading the effort to: a) better understand the psychological impacts that that are experienced by environmental researchers; and b) to suggest ideas, methods, and guidance on how environmental researchers may practise self-care.

To this end, I use the few empirical studies on the topic that I could find (Fraser et al. 2013; Head and Harada 2017; Kelly 2017; Pearse, Goodman and Rosewarne 2010; Hoggett and Randall 2018). Geographically, these studies reveal the existence of similar phenomena in different parts of the world (such as United States and Australia). However, it would be important to conduct further research in various parts of the globe and among various groups of people. These recent studies, all of which stem from the last decade, have been conducted among environmental researchers, conservationists, and students of related subjects. Because of this research background, and because there is much overlap between these fields, my discussion of 'environmental researchers' is, in effect, a discussion of all three of these groups of people. Conservationists or environmentalists often participate in research activities, and environmental researchers often participate in various kinds of environmental activism. I have occasionally used one of these terms to describe phenomena that are specifically relevant to a particular group of people among these three, but usually I use the expression 'environmental researchers' to describe all of these groups.

While the focus of this article is primarily on environmental researchers and environmentalists, most of the information and analysis also pertains to the trauma-like effects of environmental problems among the general public, such that the article can be placed in the broader field of interdisciplinary environmental studies or psychosocial research on environmental themes. 


\section{Environmental Researchers and Traumatic Stress}

According to the discussion above, it seems very possible and even probable that environmental researchers are affected by ecological trauma in several ways. A research agenda about environmental researchers and trauma, with a special focus on vicarious traumatization and secondary traumatic stress, would consider:

a) the possible traumas that environmental researchers encounter as part of their work: primary traumas (both Type 1 and Type 2) and secondary traumas (as differentiated from burnout, which is a worthy subject of its own);

b) VT and STS symptoms that environmental researchers manifest;

c) how environmental researchers relate to (varieties of) climate trauma, with special attention to climate scientists and others who directly work with climate change and its consequences;

d) the possible earlier exposures to ecological trauma, which may affect the wellbeing of environmental researchers and their vulnerability for VT and STS;

e) the ways in which environmental researchers try to cope with stress and trauma; and

f) the amount of organizational support and health-care help that is available to environmental researchers (and the amount of understanding about ecological trauma that helping professionals, who treat them, have).

In this article, I have discussed only some of these aspects. In particular, I have focused on VT and STS symptoms in the light of several empirical studies about the psychological impacts that environmental researchers experience. I have also discussed coping methods and the need for support on an organizational level.

Environmental researchers, environmentalists and students of these fields (again, in short: environmental researchers) belong to the groups of people who have been recognized as being at especially heightened risk to suffer from negative psychological impacts of environmental problems 
(Coyle and van Susteren 2012, 16-19; Cunsolo and Ellis 2018, 276). They have knowledge about the scale and severity of environmental problems, they are constantly in touch with information about these issues, and they usually have strong emotional ties with their work and with the environment (Fraser et al. 2013). Fieldwork can be especially burdening, since it provides holistic encounter with the problems. A report has called environmental researchers 'the Working Wounded' as regards the psychological impact of climate change (Coyle and van Susteren 2012, 19).

More attention should be given to the fact that it is possible for environmental researchers to suffer from primary trauma symptoms because of sudden and powerful experiences. Examples of these include an event where a gorilla researcher encounters gorillas, perhaps ones that she had known for a long time, that have been violently killed by poachers (cf. the reflections by Fossey 1983); and an encounter with a sudden clear-cut of an old-growth forest that the scholar has studied (cf, Wright 2017). However, more indirect and subtle forms of trauma seem to be more common among environmental researchers.

John Fraser et al. (2013) have made a pioneering study about emotional experiences and stress among environmentalists (they use the word 'conservationists'), utilizing what they call 'a trauma-based framework'. They combined theoretical insights and two empirical studies: questionnaires were sent to environmentalists and environmental educators, and many of them were interviewed. Many of these participants could be called environmental researchers, at least in part: they often do research and they usually are well aware of the results of latest research. The study found out that many environmentalists are in profound danger of burnout and PTSD. The scholars summarize: 'Constant contact with evidence of environmental degradation as part of one's daily work and awareness of the challenges facing the environment at the local level, such as habitat loss to development, and the global scale, with issues like climate change, may lead to acute stress 
experiences that may potentially be severe enough to be diagnosed as acute stress disorder' (70). Sometimes this phenomenon is called "eco-anxiety" (Pihkala 2018).

For example, when asked about 'degree of worry about the future environmental conditions on the planet', using a scale from 1 to $7,48,9 \%$ of the respondents choose level 7 , 'constant and persistent worry', and 38,5\% chose level 6 (72). Fraser et al. do not engage in extensive discussions about ecological trauma and they rest their case with evidence of PTSD-like symptoms. However, their results clearly support the need to further analyze climate trauma, ecological trauma and secondary trauma among environmental researchers. They point out to the fact that much of the stress that environmental researchers encounter is transmitted vicariously.

Biologist Camille Parmesan has commented the amount of psychological reactions that environmental researchers have: 'I don't know of a single scientist that's not having an emotional reaction to what is being lost. Some of these people have been studying a particular reef or a particular bird or a particular mammal for 40 to 50 years. And to start seeing it die off is a very hard thing' (quoted in Coyle and Van Susteren 2012, 19). However, as will be discussed below, this grief - which has strong links to trauma - has often remained silent.

I have compared the studies available about the psychological challenges that environmental researchers face with the symptoms of traumatic stress as described by trauma theory. The result is that there is plenty of data which shows that environmental researchers suffer from typical symptoms of traumatic stress. Researchers report constant worry, sadness, and anxiety, which are caused both by damage to the environment, by damage to people (and creatures) who suffer from such damage, and by the magnitude of the threats to ecosystems (Fraser et al. 2013; Kelly 2017, 2123; Hoggett \& Randall 2018, 230-231; Willis 2012, 57; Windle [1992] 1995). They tell of somatic symptoms (Stoknes 2015, 171-189). As for an increasingly pessimistic view of the world, the researchers report strong feelings of helplessness and hopelessness, with climate change being a major reason for this (Head and Harada 2017, 38-39; Fraser et al. 2013, 75; Kelly 2017, 21-22). 
While researchers often have found ways to deal with such feelings at least temporarily, the situation can easily lead to feelings of a lack of safety and a diminished sense of trust (for trust and climate change, see Lucas, Leith, and Davison 2015), and to changes in assumptions about other people. Among students, environmentalists, and researchers, there is for example lack of trust towards the media (Kelly 2017, 23-26) and sometimes towards politicians (23; Pearse, Goodman and Rosewarne 2010, 73).

I do not claim that trauma is necessarily always the best framework for understanding such symptoms that environmental researchers manifest. However, it is important to note that symptoms related to trauma theory exist in such a wide manner among them, and it seems that at least more attention should be given to the study of possible trauma dynamics among environmental researchers.

A major symptom of traumatic stress, alienation from others, seems to be a significant problem among environmental researchers. This phenomenon is affected by the problems related to the role of emotions on cultural and organizational levels. In industrialized societies, the role of emotions and especially those that are called 'negative emotions', including grief and anxiety, is very complex. People often feel that they should show mainly positive emotions in the public sphere. This kind of cultural politics of emotion has been criticized by several scholars as unethical and damaging (Solomon and Stone 2002; Head and Harada 2017, 36; Greenspan 2004).

Several studies have noted the existence of this problematic among environmental researchers. Fraser et al. (2013) point out that: 'educational systems and cultural norms that degrade or dismiss the role of emotion, relying primarily on intellectual analysis and environmental learning processes, may not afford environmentalists the opportunity to express emotions that plague them continually' (71). Head and Harada (2017) show that a sample of Australian climate scientists suffers from a similar phenomenon, while Hoggett \& Randall (2018) reveal similar dynamics among British climate scientists. 
As a result, environmental researchers suffer from disenfranchised grief, which is not allowed to be processed openly. In a pioneering essay in 1992, Windle already raised up this theme, pointing out both to the numerous feelings of loss that environmental researchers have and to the ways in which these emotions have been kept silent about. As a researcher, she felt that she was not allowed to express difficult emotions ([1992] 1995). It seems evident that this phenomenon should be studied more from the perspectives of trauma theory.

Studies show that the isolation that environmental researchers feel is often made worse because of their knowledge about the amount of environmental degradation and because of the fact that the general public seems unaware (although there may be knowledge which is hidden beneath denial and defences) (Fraser et al. 2013, 71; cf. Kelly 2017, 27-28; Hoggett \& Randall 2018, 240). This isolated state of environmentally conscious people has been referred in various studies to that of 'early mourners', who feel isolated in their mourning (Hamilton 2011), and 'ecological emotional outlaws', who are not given a right to express their feelings (Kretz 2017). This increases the possibilities of suffering from traumatic stress.

\section{Reactions to Traumatic Stress among Environmental Researchers}

My analysis of the existing studies shows that environmental researchers use both adaptive and maladaptive methods to cope with traumatic stress. Several studies show that environmental researchers use strategies of detachment and distancing as regards troubling emotions. Fraser et al. $(2013,77)$ comment on this phenomenon: '[conservationists'] professed detachment suggests that they are suppressing emotional work as a short-term resilience strategy despite its long-term harmful implications.' Fraser et al. fear that the cumulative toll of continuing stress and silence is so heavy that 'a breaking point will be reached eventually for most environmentalists, when such suppressed stress becomes overwhelming and manifests symptomatically' (73). Head and Harada (2017) discuss many distancing practices that climate scientists used as regards emotions, analyzing 
this through the frameworks of emotion management and emotional labor (see also Fraser and Brandt 2013). Many environmental researchers, as other people, resort to 'psychic numbing' (Norgaard 2011; Lifton 2017) or 'emotional freezing' (Orange 2017) in relation to the psychological toll. Hoggett and Randall (2018) see that the scientific community utilizes social defences in order to escape emotional burdens related to environmental distress. Psychological defences may be socially organized: for example, people at a workplace may create a jointly upheld atmosphere and belief that there are no problems at hand. This kind of behaviour often provides temporary relief but causes anxiety and burnout - trauma symptoms - in the long run. ${ }^{3}$

The study by Fraser et al. (2013) indicated that becoming overwhelmed is an especially grave danger for those conservationists who do not have strong support from family or colleagues. The problems related to isolation are thus in many ways crucial. One of the possible reactions to vicarious traumatization and secondary traumatic stress is that the environmental researchers, both knowingly and unknowingly, pass on the emotions generated by traumatic stress into others. Psychologists Clayton and Myers (2015, Chapter 12) point out this problem of maladaptive coping: 'One danger is that [environmental] activists, similar to people coping with more gut-level traumas, may pass their stress on to others (e.g., communicating gloom and doom) as a way of coping, unaware of how destructive this may be.'

This problematic could be analyzed more extensively from the point of view of trauma theory and the ways in which traumatic stress may cause problems in human relations. Trauma scholars note that those who suffer from secondary trauma 'may traumatize their families by their chronic unavailability and emotional withdrawal, perhaps in the same way that [primary] trauma victims sometimes traumatize those around them' (Salston and Figley 2003, 169). It seems probable that environmental researchers who suffer from VT and STS may also do so, but this would require further research. Similarly to clinicians working with difficult cases, environmental researchers may have the feeling that nobody outside their field can understand their difficulties, in this case because 
other people seem not to understand the extent of environmental damage. As clinicians who do not wish to speak of potentially shocking work-related matters at home, environmental researchers may withdraw from talking because of empathy towards others. (Cf. the observations about clinicians in Salston and Figley 2003.)

One way of coping with the environmental crisis is the effort to escape negative emotions and stress by trying to stay constantly busy. There is some discussion about work-a-holism as a common response to the environmental crisis (Pipher 2013; Greenspan 2004; Glendinning 1994), and 'staying busy' has been reported as one coping mechanism about climate change (Cunsolo et al. 2013). Regarding environmental researchers, the comments by Gillian Caldwell, a climate scientist and activist, are telling: 'As I started to immerse myself in the science and early impacts of global warming, I became increasingly distraught. But I soldier on, hoping against hope that I will be so busy in an ambitious new campaign and so relieved to be trying to do something about it that I will not be able to feel the angst or despair' (Coyle and van Susteren 2011, 19). Such strategies seem to be very common among many environmentalists and the work atmosphere of environmental organizations often supports them (Johnson 2018; Kelly 2017, 36), but these can be psychologically very depleting in the long term. As trauma scholars have pointed out, there should be enough time for self-treatment and enough social support for facing difficult emotions. Hoggett and Randall (2018) discovered that many climate scientists are heavily overwork, partly because they try to

escape negative emotions. They point out that the situation among environmentalists varies: in large organizations, there is a strong tendency for maladaptive coping due to organizational cultures (230, 232), but some smaller environmental organizations already practice an emotion-positive culture which encourages people to avoid overwork and to develop coping skills (234-235).

\section{Vulnerability Factors and Self-care}

In this section, I will apply insights from trauma theory into considerations of how environmental 
researchers could better cope with potential traumatic stress and related psychological impacts. The same recommendations for self-care that have been formulated for researchers from other fields, including social sciences (Whitt-Woosley \& Sprang 2018, 482), are also widely applicable for environmental researchers.

An important insight from trauma theory is the knowledge gathered about the factors that make people more vulnerable to trauma symptoms. These factors include, (1) The amount of empathy one possesses, (2) Past traumatic events one has experienced, (3) Unresolved traumatic conflicts one may harbor, (4) The amount of exposure to family, children's or friends' trauma, and (5) The degree of maladaptive responses one uses as a survival strategy (Coyle and van Susteren 2012, 10-11).

Environmental researchers and those who seek to support them psychologically should consider the implications of the aforementioned factors for them. I provide here a short discussion of these factors.

(1) The amount of empathy one possesses. It should be recognized that environmental researchers with lots of empathy for nature are at special risk to become traumatized by witnessing the suffering of nature (which often means suffering of humans at the same time). Compassion fatigue is a real threat. Figley's observation that 'Those who have enormous capacity for feeling and expressing empathy tend to be more at risk of compassion stress' (Salston and Figley 2003, 169) is relevant to environmental researchers as well. More attention is needed to guidance about psychological resilience for environmental researchers and especially those of them who engage in fieldwork (cf. the agenda for better supervision and support of post-disaster researchers by Dominey-Howes [2015, 61]).

(2) Past traumatic events one has experienced. The role of earlier experiences of ecological trauma that environmental researchers have suffered merits further attention. There are important insights to be learned here from literature on secondary traumatic stress, where it has been noted 
that many of the people who work with trauma have had traumas themselves. This can provide more understanding and motivation, but it can also be dangerous in such cases when witnessing activates previous traumas in the mind of the observer (Ellis and Knight 2018; Salston and Figley 2003).

(3) Unresolved traumatic conflicts one may harbor. It should be recognized that environmental researchers may suffer from unresolved traumatic conflicts which make them more vulnerable to ecological traumas. More attention should be given to the ways in which ongoing traumatic states may affect environmental researchers. It should be noted that these may be both cultural and individual, and the relevant literature about climate trauma should be taken into account.

(4) The amount of exposure to family, children's or friends' trauma. Environmental researchers should take note that the amount of trauma among their close ones, including their ecological traumas (and climate traumas) or eco-anxiety, affects the amount of stressors that they encounter. There are several potential dangers here. Environmental researchers may become overburdened. On the other hand, it may happen that environmental researchers start to disengage emotionally from their close ones, so that the amount of stressors would diminish. This has the potential to increase feelings of isolation and, eventually, stress. The findings by Head and Harada $(2017,38)$ which show that climate researchers do not speak of climate change at home merit attention in this regard. While such emotional management may uphold perseverance in the short term, the situation should be critically analysed. For example, the fact that the climate researchers did not speak about climate change with their children may cause psychological problems for the children, who have been reported elsewhere to suffer from the silence about climate change by adults (Brown 2016; Eaton 2017). It seems that more profound ways of processing difficult emotions, both by adults and children, would be a more lasting solution. 
5. The degree of maladaptive responses one uses as a survival strategy. The existing studies show that environmental researchers often use maladaptive coping methods. This should be recognized, and more resources should be directed to the painful but essential work of encountering difficult emotions, instead of using too many methods of distancing. A balance is needed between problem-focused coping and emotion-focused coping. Environmental researchers would benefit from further engagement with the psychological resource materials provided by environmental psychology organizations. The Australian Psychological Society has produced many such materials (for example, coping with climate change distress, and dealing with burnout and climate change) with the help of various other organizations and they are freely available online (See for example https://psychology.org.au/for-the-public/Psychology-topics/Climate-change-psychology).

A major American report includes recommendations of coping strategies which help to 'recover from climate change-related mental trauma'. These include:

1. Build belief in one's own resilience.

2. Foster optimism.

3. Cultivate active coping and self-regulation skills.

4. Maintain practices that help to provide a sense of meaning.

5. Promote connectedness to family, place, culture, and community. (Clayton, Manning, Krygsman and Speiser 2017, 7)

This set of recommendations is well suited for the understanding provided by the discussions about trauma theory and the environment in this article, except for one remark. As for optimism, I argue that in the midst of a growing ecological catastrophe, it is important to make a distinction between hope and optimism. Strictly defined, optimism (and pessimism, on the opposite end) is related to estimations of probability (cf. Head and Harada 2017, 38). Hope, instead, can be defined as a determination to continue living and to find meaningfulness, even though we cannot know how well humanity can succeed in mitigating the environmental crisis. This kind of hope has 
been called with several names, such as 'authentic hope' and 'radical hope' (Pihkala 2017). Thus, my own recommendation for coping strategies would thus be: 'Foster hope'.

\section{5. 'Survivor Mission' and Post-traumatic Growth}

Three major things deserve further attention: the special psychological resources that environmental researchers have, the role of earlier traumatic experiences, and the possibility for post-traumatic growth. People from all of the case examples used in this article - climate scientists, environmental activists, and students of related fields - have all reported that they experience both special burdens and special strengths as related to their positions. Kelly $(2017,21)$ reports: 'for many activists ... their hard work brings them great joy and fulfilment while also sometimes taking a huge toll on their emotional wellbeing' (cf. Hoggett and Randall 2018, 234). Pearse, Goodman and Rosewarne $(2010,94)$ note that: 'A recurrent theme from all participants was that hopes come from engagement with the movement.' The situation has a certain polarity, which manifests itself in the certain 'bi-polar' experiences that environmental researchers report (Fraser et al. 2013, 75; Head and Harada 2017, 39).

It seems clear that the position of environmental researchers includes both a dangerous amount of stressors and significant supporting factors. An important framework for analyzing the situation is post-traumatic growth. By using theories that describe the phases of trauma recovery, it can be said that there is a need and possibility to reach a phase of reconciliation, reconnection and integration in relation to various kinds of ecological traumas. Environmental researchers who have possibilities to process their emotions and to deal with various kinds of trauma symptoms may move further from phases of depression and acute reactions. Because much of the traumatic stress that environmental researchers encounter is transmitted vicariously, this post-traumatic growth can be analyzed through the framework of 'vicarious traumatic growth' (VTG). Studies show that VTG 
requires active measures from the person himself, such as willingness to engage in cognitive reframing and self-care (see Branson 2018, 7 and the sources cited there).

Some people reach a calmer state of mind through participating in therapy or psychological support groups. Gillespie $(2017,184)$ reports the results of her psychological support group for climate activists: 'By the end ... all participants reported back that they had experienced significant improvements in feelings of psychological wellbeing as well as increased levels of motivation and direction in relation to climate change engagement.' Others make their way through by finding a community and by practicing self-help (Kelly 2017, 29-32; Stoknes 2015, chapters 15 and 18; cf. many of the letters in http://www.isthishowyoufeel.com). Some of the environmental activists interviewed by Hoggett and Randall (2018) had developed both communal and individual ways of coping and self-care (234-235). One of them comments: "We have Activist Trauma Support, we have medical support, we have debriefings, we have a really good way of helping people. We know what burnout is now. We know what post-traumatic stress disorder is" (235). Various methods for peer group work have been generated in recent years. These include the peer group method developed by the Good Grief Network (http://www.goodgriefgroup.org/) and the activities provided by the Radical Joy network (Johnson 2018; Johnson 2017;

https://www.radicaljoyforhardtimes.org/).

An important part of recovery and healing is the possibility to help others who have suffered from similar traumas. There is some discussion about this in literature related to psychological impacts of environmental problems, but more attention would be needed to this possibility. Psychiatrist Robert Jay Lifton's insights about being a survivor have been applied into environmental matters: those who have suffered from ecological trauma, and have survived, have influential possibilities to help others (Nicholsen 2002, 154-156; Lifton 2017, 146-148, 153-156). Providing help to others also helps the helpers. Rayner (2005) writes about this 'survivor mission' in relation to ecological trauma: 'As activists, our survivor mission is nothing less than the 
establishment of a new human culture based on harmony with the rest of nature.' Psychological surviving and physical, civilization-level survival become connected.

Scholars of secondary traumatic stress have found out that 'many victim service providers select into the field because of personal experiences with primary trauma' (Ellis and Knight 2018, 19). As for environmentalists and environmental researchers, the same applies as regards witnessing ecological trauma. ${ }^{4}$ There are two important points to note here. First, there is increased vulnerability because of earlier trauma exposure, and the warnings of STS scholars about the increased possibility for secondary trauma among such 'helpers' should be taken seriously (Ellis and Knight 2018, 19-20; Salston and Figley 2003, 170). Second, this kind of earlier history can also provide increased motivation and potentially skills for survivor knowledge.

Thus, for environmental researchers, their choice of profession can already be seen to be a potential step for manifesting post-traumatic growth and performing an empowering survivor mission. An example is Ashlee Cunsolo (Willox), who tells of her experiences of ecological trauma during her childhood $(2012,137) .{ }^{5}$ Later, she became a researcher of environmental change and loss, and her pioneering scholarship about ecological grief (Cunsolo \& Landman 2017; Cunsolo \& Ellis 2018) has received many comments from environmental researchers who thank her (and her colleagues) for finally taking up this emotional dimension (Simon 2018). It can be said that Cunsolo has been able to help others because of survivor knowledge.

Many psychologists and especially ecopsychologists recommend spending time in natural settings as an important means for coping (see, for example, the materials by The Australian Psychological Society mentioned above). It seems that this is a highly important thing for many environmentalists (Hoggett and Randall 2018, 235) and environmental researchers, even though the situation is complex: as Fraser and al. (2013) point out, the researchers also experience stress in nature, because they know the extent of damage done to it. It can be formulated that one of the challenges (and benefits) of post-traumatic growth is that an environmental researcher is able to also 
enjoy her time in nature, even though there is at the same time the knowledge of its fragility. This is one important part of developing skills to live with ambiguity and a benefit of being able to experience various emotions, both grief and joy.

\section{Conclusions}

In this article, I have discussed the ways in which environmental researchers, environmentalists and students of related fields (later: environmental researchers) may suffer from vicarious trauma (VT) and Secondary Traumatic Stress (STS). Environmental researchers encounter traumatic issues such as the scale of global and local environmental problems, feelings of isolation because of their knowledge and the existence of socially constructed silence, and feelings of helplessness because political engagement seems to be too slow to solve the problems.

By analyzing existing empirical studies, I concluded that environmental researchers manifest many symptoms which are well captured by trauma theory. I argued that more attention is needed to possible primary ecological traumas among environmental researchers, but that it seems that much traumatic stress is encountered by them in a vicarious manner. Often VT seems the best framework for understanding ecological trauma among environmental researchers, but also further study of STS symptoms would be in order. It seems that trauma theory is not much discussed by environmental researchers (or environmentalists) and that it could provide important insights for both people themselves.

By becoming more acquainted with the insights provided by trauma theory, environmental researchers and environmentalists may themselves find wisdom to practice better coping methods. They should monitor the stress levels that they are experiencing, discuss (and practice) coping methods collectively, and demand psychological support from the organizations which employ them. The amount of exposure to vicariously traumatizing information, such as news about environmental degradation, should be controlled for example by limiting constant media exposure. 
Since feelings of isolation have been found out to be a common threat among environmentalists, it is crucially important to build social networks of support and sharing.

In order to maintain resilience and to avoid or treat too much (secondary) traumatic stress, environmentalists would benefit from methods that have been developed to personnel from other fields as regards treatment of STS. There is a need for discussions and initiatives that help institutions and organizations, including environmental research institutes, environmental organizations and educational institutes, to develop a) better practices and b) an atmosphere that is more sensitive and accepting towards negative emotions.

Concerning those who work in health care and social work, there is a need to become more acquainted with phenomena related to ecological trauma (and eco-anxiety). As scholars have recommended: 'Community counsellors and social workers would be well served to receive further training in climate and environment-based emotional traumas, and to work with individuals to foster emotional health and strength in the context of a changing environment' (Cunsolo et al. 2013, 22).

I emphasize that it is important to further integrate trauma theory with other theories about the psychological impacts of environmental problems, so that the symptoms among environmental researchers can be better understood and alleviated. In other words, we need more discussion about the relations between such approaches as ecological grief, eco-anxiety, psychological impacts of climate change (sometimes called 'climate psychology'), and varieties of ecological trauma. Scholars such as Joseph Reser have provided important discussions on various frameworks that may be utilized in order to analyze people's reactions to environmental problems (Reser, Morrissey, and Ellul 2012; Bradley and Reser 2017). Frameworks of coping and adaptation, and of dealing with anxiety, have already received attention, but further work should be done to discuss the relation of these approaches to the insights about trauma theory. My article is a modest beginning in this integrative work. 
It seems evident that amidst a deepening global environmental crisis, there will be an increased need to pay attention to its psychological impacts. Environmental researchers, environmentalists, and students of related fields are all people who are in a special position as regards the opportunities for building more resilience in societies in general. ${ }^{6}$ They are also among the people who are especially burdened by the impacts of environmental problems. It is thus of extraordinary importance that more support is found for them. By taking better care of environmental researchers, larger populations are also helped. In right conditions, environmental researchers can also serve as examples of post-traumatic growth and function as important sharers of survivor knowledge.

\section{Acknowledgements}

I thank the editors and the anonymous peer reviewer for their insightful comments about my manuscript. Their diligence helped to improve this article.

\section{Disclosure Statement}

No potential conflict of interest was reported by the author.

\section{Funding Details}

This work was supported by a grant from Ella and Georg Ehrnrooth Foundation. 


\section{References}

Berry, Helen, Thomas D. Waite, Keith B. G. Dear, Anthony G. Capon, and Virginia Murray. 2018. "The Case for Systems Thinking about Climate Change and Mental Health." Nature Climate Change 8 (4): 282-290.

Bradley, Graham L., and Joseph P. Reser. 2017. "Adaptation Processes in the Context of Climate Change: A Social and Environmental Psychology Perspective." Journal of Bioeconomics 19 (1): 29-51.

Branson, Dana C. 2018. "Vicarious Trauma, Themes in Research, and Terminology: A Review of Literature." Traumatology. Advance online publication. doi: 10.1037/trm0000161

Brennan, Andrew. 2015. “Environmental Ethics.” Stanford Encyclopedia of Philosophy. http://plato.stanford.edu/entries/ethics-environmental/\#toc

Brown, Molly Young. 2016. "Supporting Children Emotionally in Times of Climate Disruption." In Education in Times of Environmental Crises, edited by Ken Winograd, 195-209. New York \& London: Routledge.

Clayton, Susan, Christie Manning, Kierra Krygsman, and Meighen Speiser. 2017. Mental Health and Our Changing Climate: Impacts, Implications, and Guidance. Washington, DC: APA and ecoAmerica.

Clayton, Susan, and Gene Myers. 2015. Conservation Psychology: Understanding and Promoting Human Care for Nature. 2nd ed. West Sussex: John Wiley \& Sons Ltd.

Collins, Barbara G., and Thomas M. Collins. 2005. Crisis and Trauma: Developmental-Ecological Intervention. Boston \& New York: Lahaska Press \& Houghton Mifflin.

Coyle, Kevin J., and Lise Van Susteren. 2012. The Psychological Effects of Global Warming on the United States: And Why the U.S. Mental Health Care System is Not Adequately Prepared. Reston: National Wildlife Federation.

Cunsolo Willox, Ashlee. 2012. "Climate Change as the Work of Mourning." Ethics \& the Environment 17 (2): 137-164.

Cunsolo Willox, Ashlee and Neville R. Ellis. 2018. "Ecological Grief as a Mental Health Response to Climate Change-Related Loss." Nature Climate Change 8 (4): 275-281.

Cunsolo Willox, Ashlee, Sherilee L. Harper, Victoria L. Edge, Karen Landman, Karen Houle, James D. Ford, and the Rigolet Inuit Community Government. 2013. "'The Land Enriches the Soul:' on Climatic and Environmental Change, Affect, and Emotional Health and Well-being in Rigolet, Nunatsiavut, Canada." Emotion, Space and Society 6 (1): 14-24.

doi:10.1016/j.emospa.2011.08.005.

Cunsolo Willox, Ashlee and Karen Landman, eds. 2017. Mourning Nature: Hope at the Heart of Ecological Loss \& Grief. Montreal \& Kingston: McGill-Queen's University Press. 
Davenport, Leslie. 2017. Emotional Resiliency in the Era of Climate Change: A Clinician's Guide. London: Jessica Kingsley Publishers.

Doherty, Thomas J. 2015. "Mental Health Impacts." In Climate Change and Public Health, edited by Barry Levy and Jonathan Patz, 195-214. Oxford \& New York: Oxford University Press.

Doherty, Thomas J., and Susan Clayton. 2011. "The Psychological Impacts of Global Climate Change." American Psychologist 66 (4): 265-276.

Dominey-Howes, Dale. 2015. "Seeing 'the Dark Passenger' - Reflections on the Emotional Trauma of Conducting Post-Disaster Research." Emotion, Space and Society 17: 55-62.

doi:10.1016/j.emospa.2015.06.008.

Eaton, Marie. 2017. "Navigating Anger, Fear, Grief, and Despair." In Contemplative Approaches to Sustainability in Higher Education: Theory and Practice, edited by Marie Eaton, H. J. Hughes, and J. McGregor, 40-54. New York: Routledge.

Ellis, Colter, and Kelly E. Knight. 2018. “Advancing a Model of Secondary Trauma: Consequences for Victim Service Providers." Journal of Interpersonal Violence. Advance online publication. 127. doi: $10.1177 / 0886260518775161$

Figley, C. R. 1999. "Compassion fatigue: Toward a new understanding of the costs of caring." In Secondary traumatic stress: Self-care issues for clinicians, researchers, \& educators, 2nd ed., edited by B. H. Stamm, 3-28. Lutherville, MD: Sidran Press.

Fossey, Dian. 1983. Gorillas in the Mist. Boston: Houghton Mifflin.

Fraser, John, and Carol B. Brandt. 2013. "The Emotional Life of the Environmental Educator.” In Trading Zones in Environmental Education, edited by M. E. Krasny and J. E. Dillon, 133-158. Oxford: Peter Lang.

Fraser, John, Victor Pantesco, Karen Plemons, Rupanwita Gupta, and Shelley J. Rank. 2013. "Sustaining the Conservationist." Ecopsychology 5 (2): 70-79.

Gillespie, Sally. 2017. "Climate Change Imaginings and Depth Psychology: Reconciling Present and Future Worlds." In Environmental Change and the World's Futures: Ecologies, Ontologies and Mythologies, edited by Jonathan P. Marshall and Linda H. Connor, 181-195. New York: Routledge.

Glendinning, Chellis. [1994] 2007. My Name is Chellis and I'm in Recovery from Western Civilization. Gabriola Island: New Catalyst Books.

Greenspan, Miriam. 2004. Healing Through the Dark Emotions: The Wisdom of Grief, Fear, and Despair. Boulder: Shambhala.

Hamilton, Clive. 2011. Requiem for a Species: Why We Resist the Truth about Climate Change. New York: Earthscan.

Harvey, Mary R., and Pratyusha Tummala-Narra. 2007. Sources and Expressions of Resiliency in Trauma Survivors: Ecological Theory, Multicultural Practice. Binghamton, NY: Haworth Maltreatment \& Trauma Press. 
Head, Lesley and Teresa Harada. 2017. "Keeping the Heart a Long Way from the Brain: The Emotional Labour of Climate Scientists." Emotion, Space and Society 24: 34-41.

Herman, Judith. 1992. Trauma and Recovery: The aftermath of violence from domestic abuse to political terror. New York: Basic Books.

Hoggett, Paul and Rosemary Randall. 2018. "Engaging with Climate Change: Comparing the Cultures of Science and Activism.” Environmental Values 27: 223-243. doi:

$10.3197 / 096327118 X 15217309300813$

Johnson, Trebbe. 2018. Radical Joy for Hard Times: Finding Meaning and Makin Beauty in Earth's Broken Places. Berkeley: North Atlantic Books.

Johnson, Trebbe. 2017. 101 Ways to make Guerrilla Beauty. [USA]: Radjoy Press.

Kaplan, E. Ann. 2016. Climate Trauma: Foreseeing the Future in Dystopian Film and Fiction. New Brunswick, NJ and London: Rutgers University Press.

Kelly, Anna. 2017. Eco-Anxiety at University: Student Experiences and Academic Perspectives on Cultivating Healthy Emotional Responses to the Climate Crisis. Independent Study Project (ISP) Collection 2642. The University of Colorado at Boulder \& Melbourne.

http://digitalcollections.sit.edu/isp_collection/2642

Kretz, Lisa. 2017. "Emotional Solidarity: Ecological Emotional Outlaws Mourning Environmental Loss and Empowering Positive Change." In Mourning Nature: Hope at the Heart of Ecological Loss \& Grief, edited by Ashlee Cunsolo Willox and Karen Landman, 258-291. Montreal \& Kingston: McGill-Queen's University Press.

Lifton, Robert Jay. 2017. Climate Swerve: Reflections on Mind, Hope, and Survival. New York: The New Press.

Lucas, Chloe, Peat Leith, and Aidan Davison. 2015. "How climate change research undermines trust in everyday life: a review." WIREs Clim Change 6, 79-91. doi: 10.1002/wcc.320

Mahon, Peter. 2017. Posthumanism: A Guide for the Perplexed. London: Bloomsbury.

Morton, Timothy. 2013. Hyperobjects: Philosophy and Ecology after the End of the World. Minneapoli: University of Minnesota Press.

Nicholsen, Shierry Weber. 2002. The Love of Nature and the End of the World: The Unspoken Dimensions of Environmental Concern. Cambridge: MIT Press.

Norgaard, Kari Marie. 2011. Living in Denial: Climate Change, Emotions, and Everyday Life. Cambridge: MIT Press.

Orange, Donna. 2017. Climate Change, Psychoanalysis, and Radical Ethics. New York: Routledge. 
Parkes, Colin Murray. 2015. "Responding to grief and trauma in the aftermath of disaster." In Death, Dying, and Bereavement: Contemporary Perspectives, Institutions, and Practices, edited by Attig, Thomas, and Judith M. Stillion, 363-378. New York: Springer Publishing Company.

Pearse, Rebecca, James Goodman, and Suart Rosewarne. 2010. "Researching Direct Action against Carbon Emissions: A Digital Ethnography of Climate Agency." Cosmopolitan Civil Societies: An Interdisciplinary Journal 2 (3): 76-103.

Pihkala, Panu. 2018. "Eco-anxiety, Tragedy, and Hope: Psychological and Spiritual Dimensions of Climate Change." Zygon 53 (2): 545-569.

Pihkala, Panu. 2017. "Environmental Education After Sustainability: Hope in the Midst of Tragedy." Global Discourse 7 (1): 109-127.

Pipher, Mary. 2013. The Green Boat: Reviving Ourselves in our Capsized Culture. New York: Riverhead Books.

Rayner, Lisa. 2005. "Ecological Collapse, Trauma Theory and Permaculture." Resilience. https://www.resilience.org/stories/2005-10-29/ecological-collapse-trauma-theory-and-permaculture/

Reser, Joseph P., Shirley A. Morrissey, and Michelle Ellul. 2011. "The Threat of Climate Change: Psychological Response, Adaptation, and Impacts." In Climate Change and Human Well-being: Global Challenges and Opportunities, edited by Inka Weissbecker, 19-42. New York: Springer.

Richardson, Michael. 2018. "Climate Trauma, Or the Affects of the Catastrophe to Come." Environmental Humanities 10 (1): 1-19. doi:10.1215/22011919-4385444.

Salston, MaryDale, and Charles R. Figley. 2003. "Secondary Traumatic Stress Effects of Working With Survivors of Criminal Victimization.” Journal of Traumatic Stress 16 (2), 167-174.

Simon, Matt. 2018. "Climate change's looming mental health crisis.” Wired, February 8. https://www.wired.com/story/climate-changes-looming-mental-health-crisis/

Solomon, Robert C., and Lori D. Stone. 2002. "On 'Positive' and 'Negative' Emotions." Journal for the Theory of Social Behaviour 32 (4): 417-435.

Stoknes, Per Espen. 2015. What we Think about when we Try Not to Think about Global Warming: Toward a New Psychology of Climate Action. White River Junction: Chelsea Green Publishing.

Terr, Lenore C. 1991. "Childhood traumas: An outline and overview." American Journal of Psychiatry, 148 (1), 10-20.

White, Benjamin. 2015. "States of Emergency: Trauma and Climate Change." Ecopsychology 7 (4): 192-197.

Whitt-Woosley and Sprang 2018 Whitt-Woosley, Adrienne, and Ginny Sprang. 2018. "Secondary Traumatic Stress in Social Science Researchers of Trauma-Exposed Populations." Journal of Aggression, Maltreatment \& Trauma, 27 (5), 475-486. doi: 10.1080/10926771.2017.1342109 
Willis, Alette. 2012. "Constructing a Story to Live by: Ethics, Emotions and Academic Practice in the Context of Climate Change." Emotion, Space and Society 5 (1): 52-59.

doi:doi:10.1016/j.emospa.2011.03.001.

Windle, Phyllis. [1992] 1995. "The Ecology of Grief." In Ecopsychology: Restoring the Earth, Healing the Mind, edited by Theodore Roszak, Mary E. Gomes and Allen D. Kanner, 126-145. San Francisco: Sierra Club.

Woodbury, Chiva. 2019. "Climate Trauma: Towards a New Taxonomy of Trauma.” Ecopsychology 11 (1). doi: 10.1089/eco.2018.0021

2018. "Climate Trauma: The New Psychology of the Climate Crisis." Article draft. https://ciis.academia.edu/ThubtenZhiwa

Woodbury, Chiva. 2016. Climate Sense: Changing the Way We Think \& Feel About Our Climate in Crisis. San Bernardino: Independently published.

Woolbright, Lauren. 2011. "Wounded Planet, Wounded People: The Possibility of Ecological Trauma." Thesis, Clemson University, number 1058. https://tigerprints.clemson.edu/all_theses/1058

Wright, Kate. 2017. Transdisciplinary Journeys in the Anthropocene: More-than-Human Encounters. Routledge Environmental Humanities. London \& New York: Routledge.

\section{Endnotes}

${ }^{1}$ I am full aware of the vast academic discussion of the problems included in defining exactly what 'environment' (or 'nature') mean. My strong view is that enough clarity can be maintained without extensive discussions about the exact meaning of these words (which is contextual). For the purposes of this article, 'environmental' refers mainly to events and threats related to environmental problems: damage of threat of damage to ecosystems and their inhabitants.

'Ecological', strictly speaking, is more related to the complexity and inter-relationality studied by ecology, but also this term is often used to refer to environmental problems.

${ }^{2}$ For example, the closest discussion to environmental problems that Collins and Collins (2005) includes is about treating traumas generated by 'losing a pet' (332). It would be interesting and potentially influential to integrate the discussions in these kind of works - such as the discussion about 'an ecological understanding of resilience in trauma survivors' (Harvey and Tummala-Narra 2007) - into the less anthropocentric theories about ecological trauma that I discuss in my article, but this falls mainly out of the scope of this article.

${ }^{3}$ In their study about psychosocial dimensions of environmental concern, Hoggett and Randall (2018) interviewed both environmental activists and researchers. They observed that many activists, in the UK, had severe experiences of stress and burnout, and based on this experience they had developed communal ways to deal with psychological pressure. The climate scientists, however, suffered from lack of institutional or communal support for their emotional burdens.

Hoggett and Randall approached this problem from the point of view of a theory of social defences. They argue (235): "Scientific culture ... creates social defences that seem to have made any working-through of anxieties unnecessary, a source of ambivalence, or a source of continual difficulty and pain. The scientists described several characteristics of science and its practice that we thought protected people against anxiety, but they also described points where these social defences were breached. The characteristics we identified as performing these defensive functions were ideas of scientific progress, scientific detachment, rationality and specialisation, scientific excitement and the normalisation of overwork." I received information about their research only at a stage when my article was nearly finished. This is the reason why I have not extensively engaged in discussing with Hoggett and Randall's research, although I refer to the many similar results that they share with the other studies I use in my article.

${ }^{4}$ See Willis $(2012,54)$, for an example how feelings related to climate trauma drove one researcher into climate research: 'I was motivated to pursue a dissertation related to climate change because I was anxious about the future and about the alterations I already perceived in local ecologies. I was frustrated by the lack of action being taken and griefstricken at the predicted loss of life. The scale of the problem and the potential for destruction engendered feelings that at times threatened to overwhelm me.' 
5 'When I was five, a pond and thicket area down the street from my house was filled in and leveled while I was away. I remember coming home and finding my beloved ecosystem denuded of all greenery, and completely empty of the beavers and their dam, the minnows, the birds, and the countless rabbits and squirrels that had been a comforting and valued presence. I was devastated. Consumed and overcome by grief and loss. I did not want to eat, or play, or go to school. I felt as though I had lost something deeply important, and intimately a part of the fabric of my life' (Cunsolo Willox 2012,137). These symptoms are clearly connected to trauma, even when various frameworks can be applied to analyze them. Cunsolo herself uses grief theory in this context.

${ }^{6}$ In the winter 2019, the several petitions by environmental researchers for climate action, and for support to the children who have practiced climate action -oriented school strikes in the vein of Greta Thunberg, seem to have functioned both as means for practicing social responsibility and as a means for psychological (adaptive) coping. 